\title{
La visita de Luján de Vargas a Catamarca. Tierra, tributo y servicio personal (1693)
}

\author{
Santiago Conti"
}

Fecha de recepción: 17 de abril de 2020. Fecha de aceptación: 25 de junio de 2020

\begin{abstract}
Resumen
Entre 1692 y 1694 Luján de Vargas realizó una visita a la gobernación del Tucumán con el objeto de desagraviar a los indios encomendados y renovar la aplicación de las ordenanzas de Alfaro. Nos proponemos indagar acerca de cuáles eran las características particulares de la jurisdicción de Catamarca que la diferenciaban del resto de la gobernación. No se trata de un estudio comparativo, sino de caso. Consideramos que estas particularidades están directamente relacionadas con la singular dinámica de conquista que tuvo la jurisdicción, pues otorgó a los feudatarios una amplia libertad para evadir las ordenanzas de Alfaro y ofreció a los indígenas menores posibilidades de adaptación al sistema colonial. Esto dio lugar a la aparición de una forma de encomienda doméstica y a la debilidad de los pueblos de indios. Aquí analizamos las características del sector encomendero, las particularidades del servicio personal en Catamarca y las formas de acceso indígena a la tierra.
\end{abstract}

\section{Luján de Vargas' visita to Catamarca. Land, tribute and personal service (1693)}

\begin{abstract}
Between 1692 and 1694 Luján de Vargas conducted a visita (inspection) of the Tucumán governorship in order to listen make reparations to the Indians to reinforce the ordenanzas de Alfaro. This study aims to inquire into the jurisdiction's particular characteristics that distinguish it from the rest of the governorship. It is not a comparative study but a case study. We consider these particularities are related to the singular dynamic of conquest in this jurisdiction, which bestowed a high degree of power on the encomenderos, allowing them to ignore the ordenanzas while leaving little room for the Indians to adapt to the colonial system. This resulted in a particular way of Indian labor, the domestic encomienda, and contributed to the weakness of the Indian towns. In this article we shall analyze the characteristics of the encomenderos as a group, the particularities of personal service in Catamarca, and the forms of Indian access to land.
\end{abstract}

Palabras clave

encomienda doméstica tierra

pueblos de indios

Catamarca

\section{Key words}

domestic encomienda land Indian towns Catamarca 


\section{Introducción}

Hace décadas, Ana María Lorandi, definió al Tucumán colonial como una región de frontera, con poca injerencia del Estado colonial y gran protagonismo de los intereses particulares que dotaban a los encomenderos de amplia libertad de acción. Estas condiciones permitieron la explotación de los indígenas bajo servicio personal, forma que había sido abolida en las zonas centrales del virreinato del Perú. Partiendo de un análisis a escala regional, para la autora esta forma de explotación, sumada a la guerra, la desposesión de tierras y huidas de indios, había tenido profundas consecuencias desestructurantes sobre las sociedades indígenas (Lorandi, 1988a).

Estudios posteriores matizaron la hipótesis de Lorandi, centrándose ya no en los efectos desestructurantes sino en las posibilidades de adaptación y resistencia de los indígenas al nuevo contexto colonial. Dichos trabajos dieron cuenta de un progresivo avance del estado colonial en la región y de la transformación del sistema tributario (Palomeque, 2000; Farberman y Gil Montero, 2002; Farberman y Boixadós, 2006; Castro Olañeta, 2006 y 2010; Carmignani, 2013, entre otros). A diferencia del estudio de Lorandi, estas nuevas investigaciones se centraron en casos puntuales -a escalas más pequeñas.

Dicho cambio de enfoque tenía su correlato en los cambios que se habían desarrollado en la Etnohistoria Andina a nivel internacional. En efecto, los estudios habían pasado de un enfoque a nivel macro, centrado en las consecuencias desestructurantes de la conquista -con Nathan Wachtel como gran exponente de la corriente-, a estudios de caso interesados en indagar sobre la capacidad de adaptación de las sociedades indígenas, entre los que destacaban los de Steve Stern (Paz, 2008).

1. La región del oeste catamarqueño, que correspondía al curato de Londres, abarcaba todo el territorio al oeste de las sierras de Ambato hasta la cordillera, incluyendo la región de la Puna, los actuales departamentos de Belén, Andalgalá, Santa María, Tinogasta, Pomán y Antofagasta de la sierra. La totalidad de esta región pertenecía a la jurisdicción de Londres, la región del valle de Catamarca correspondía al curato del valle y abarcaba el espacio comprendido entre las sierras de Ancasti y El Alto al este, y las sierras de Ambato al oeste, territorio que ocupan los actuales departamentos de Ambato, Paclin, Fray Mamerto Esquiú, Valle Viejo, Capital y Capayán. Hasta la creación de la jurisdicción de Catamarca, esta región dependía de las jurisdicciones de La Rioja -su parte sur- y San Miguel de Tucumán -su parte norte-. Finalmente, la tercera región era el este catamarqueño, que comprendía la vertiente oriental de las sierras de El Alto-Ancasti, englobada dentro del curato de Maquijata; esta zona abarcaba los actuales departamentos de Santa Rosa, El Alto, Ancasti y La Paz. El este catamarqueño dependió de la jurisdicción de Santiago del Estero hasta 1683 (Guzmán, 1986; Brizuela del Moral y Acuña, 2002).

En este trabajo, sin embargo, pretendemos recuperar la importancia del proceso de desestructuración como característica fundamental del espacio catamarqueño pues dio lugar a un desarrollo distinto al resto de las jurisdicciones de la gobernación, lo cual impidió una transformación en el sistema tributario en contraste con otras zonas del Tucumán. A continuación, presentamos las características de la dinámica de conquista del espacio, ya que consideramos que fue ésta la que dotó a Catamarca de sus particularidades distintivas.

\section{La conquista del espacio catamarqueño}

La jurisdicción de Catamarca fue creada en 1683 con la fundación de la ciudad de San Fernando del Valle de Catamarca y pasó a englobar, en una misma unidad, territorios anteriormente pertenecientes a jurisdicciones distintas: Londres, La Rioja, San Miguel de Tucumán y Santiago del Estero (Brizuela del Moral y Acuña, 2002). Este territorio puede ser separado en tres regiones, el oeste catamarqueño, el valle de Catamarca y el este catamarqueño, que correspondían a la división de los curatos de principios del siglo XVII. ${ }^{1}$ En lo sucesivo, cuando nos refiramos a Catamarca, o al espacio catamarqueño, estaremos hablando del conjunto de estas tres regiones que formaban la jurisdicción.

Desde sus inicios, la penetración española en Catamarca fue dificultosa. La primera ciudad en territorio catamarqueño fue Londres, fundada en 1558 por Pérez de Zurita en el valle de Hualfín, dando lugar a la jurisdicción homónima. Con la fundación el Gobernador repartió mercedes de tierras y de encomiendas, pero Londres fue rápidamente destruida por la rebelión de Juan 
Calchaquí y su territorio pasó a depender de la ciudad de La Rioja, fundada posteriormente en 1591. En 1607, Londres fue refundada por vecinos riojanos bajo el nombre de San Juan Bautista de la Ribera. Su refundación respondía a un doble objetivo: por un lado, establecer un control efectivo sobre los grupos indígenas del valle de Hualfín, que estaban legalmente encomendados pero que al mantenerse independientes no cumplían con las obligaciones laborales; por otro lado, se pretendía que la entrega de mercedes de encomiendas y tierras sirviera como válvula de escape a los conflictos por dichos recursos entre los vecinos de La Rioja. Con la refundación de la ciudad los indígenas comenzaron a ser explotados bajo régimen de servicio personal (Quiroga, 2012).

El servicio personal había sido prohibido en las zonas centrales del virreinato del Perú, pero había sido legalizado por las ordenanzas de Abreu en la gobernación del Tucumán en 1576. Según Ana María Lorandi, bajo este régimen de explotación: "el trabajo de los indios, en realidad, consistía en una superposición de obligaciones que debía cumplir mediante la llamada mita al encomendero", sin ningún tipo de tasación (Lorandi, 1988a: 148). Esto dio lugar a que los indígenas trabajaran para su feudatario a tiempo completo de manera compulsiva, sin tener tiempo para dedicar a la reproducción de la comunidad. ${ }^{2}$ Esta forma de trabajo, sumada a los avances sobre las tierras de las comunidades, los traslados y las sacas de indios de los pueblos, tuvo un fuerte impacto desestructurante sobre las sociedades indígenas en toda la gobernación. Dicha desestructuración implicó la estrepitosa caída de la población indígena, el despoblamiento de los pueblos, las huidas, la fragmentación de las comunidades y la progresiva desaparición de autoridades étnicas (Lorandi, 1988a). En la jurisdicción de Londres, las comunidades indígenas vieron fuertemente comprometida su capacidad de reproducción. En este caso, una de las características centrales del servicio personal fue la importancia de la exigencia de hilados hacia las indias, que trabajaban a tiempo completo (Quiroga, 2012: 24).

En 1612, la gobernación del Tucumán fue visitada por el oidor de la Audiencia de Charcas, don Francisco de Alfaro, quien redactó una serie de ordenanzas que modificaron fuertemente la legislación que regulaba las formas de explotación de los indígenas. Como medidas más importantes, Alfaro tasó el tributo en cinco pesos, prohibió el servicio personal y redujo a los indígenas en pueblos de indios, entre otras disposiciones (Palomeque, 2000). Estas ordenanzas fueron fuertemente resistidas por los feudatarios pero, poco a poco, se comenzaron a aplicar en el Tucumán. ${ }^{3}$ Silvia Palomeque propuso que su aplicación dependió de la capacidad de los indígenas de hacerla cumplir (Palomeque, 2000: 133). Trabajos posteriores demostraron que, de manera disímil en diversas áreas de la gobernación, a lo largo del siglo XVII se había producido una transformación del sistema tributario bajo la aplicación de las ordenanzas de Alfaro (Farberman y Gil Montero, 2002; Farberman y Boixadós, 2006; Castro Olañeta, 2010, entre otros).

Sin embargo, dicha transformación no se dio en Catamarca. Es probable que,al haber sido Londres una zona marginal dentro de la gobernación del Tucumán los encomenderos hubieran tenido mayor capacidad de eludir las ordenanzas de Alfaro, en comparación a otras jurisdicciones. ${ }^{4}$ La refundación de la ciudad de Londres en un espacio poblado de indígenas hostiles implicaba una empresa riesgosa que exigía una recompensa acorde para los encomenderos; y éstos consideraban que la mayor riqueza se encontraba en la fuerza de trabajo indígena. Además, dada la hostilidad de los indios de la región los encomenderos cumplían un rol central para asegurar el control efectivo del territorio.
2. Las ordenanzas de Abreu constituyeron un primer intento de regulación del servicio personal pero a la vez implicaron la legalización de la práctica. Para un análisis pormenorizado de las ordenanzas de Abreu ver Doucet (1990).

3. Leticia Carmignani (2013) señala que antes de la visita de Alfaro y la redacción de sus ordenanzas, las visitas ordenadas por el gobernador Alonso de Ribera fueron una primera intervención sobre el poder de los encomenderos que buscaba limitar la explotación de los indígenas de acuerdo a lo establecido por las ordenanzas de Abreu.

4. A partir del análisis de la visita del gobernador Quiñones Osorio en Córdoba, Isabel Castro Olañeta dio cuenta del intento del gobernador de hacer una aplicación manipulada de las ordenanzas de Alfaro para beneficiar a los encomenderos y legalizar y esconder la continuidad del servicio personal. Sin embargo, la autora aclara que la visita muestra un momento donde se están institucionalizando nuevas relaciones entre indios y encomenderos, por lo que no debe pensarse en una simple continuidad del servicio personal prealfariano (Castro Olañeta, 2010: 124). 
Todo esto seguramente haya contribuido a otorgar una mayor libertad a los feudatarios a la hora de no aplicar las ordenanzas de Alfaro.

Los efectos desestructurantes generados por la continuidad del servicio personal pusieron en peligro la capacidad de reproducción de las sociedades indígenas y motivaron un levantamiento conocido, como Gran Alzamiento Diaguita (1630-43). El alzamiento tuvo su centro en el oeste catamarqueño, encabezado por Chalemín, cacique de los malfines, pero luego se extendió a La Rioja y el sur de los valles Calchaquíes. La ciudad de San Juan Bautista fue sitiada por los indígenas en 1632, debió ser abandonada y todas las propiedades españolas en la región fueron destruidas. La rebelión fue definitivamente sofocada en 1643 y los rebeldes fueron castigados con la desnaturalización (Lorandi, 1988b). San Juan Bautista fue refundada en 1633 en el paraje de Pomán, en el oeste catamarqueño, pero nunca tuvo población permanente.

A mediados del siglo XVII, la gobernación del Tucumán volvió a ser escenario de rebeliones indígenas con la llegada del falso inca Pedro Bohórquez. Esta vez, el levantamiento se circunscribió a los valles Calchaquíes, cuya parte sur -el valle de Santa María- se encontraba dentro del territorio catamarqueño (Lorandi, 1988b). El gobernador Mercado y Villacorta organizó dos campañas que terminaron con la definitiva derrota de los rebeldes, su desnaturalización y repartimiento en encomiendas. Para lograr el reclutamiento de tropas, el Gobernador prometió que los soldados que participaran de las campañas serían premiados con indígenas capturados. Con este fin, dictó una serie de autos donde establecía la modalidad de inserción de los desnaturalizados en el sistema de encomiendas. Para aquellos que fueron situados en tierras privadas de los feudatarios se establecía que debía señalárseles tierras para su sustento. Por su parte, los autos eximían de tributo a los desnaturalizados por el plazo de diez años. El resultado fue que estos indios fueron explotados en su mayoría bajo servicio personal (Boixadós, 2011; Zelada y Castro Olañeta, 2017). El desenlace de esta rebelión significó un parte aguas para la gobernación porque terminó definitivamente con más de un siglo de resistencia indígena en los valles. Pero, además, para el caso de Catamarca, tuvo una relevancia central porque dotó a la jurisdicción de una gran cantidad de indígenas desnaturalizados que fueron repartidos a los soldados, dando lugar a la formación de un número elevado de nuevas encomiendas diminutas. Dicho proceso resultó fundamental para la configuración de un tipo de encomienda catamarqueña con características particulares, como veremos a continuación.

De esta manera, consideramos que la guerra resultó un factor central de la dinámica de colonización del espacio catamarqueño. En este sentido, pretendemos recuperar la hipótesis de la desestructuración planteada por Lorandi (1988a) para el análisis específico de este espacio dado que, debido a la tenaz resistencia de los indígenas, Catamarca fue una zona de frontera donde los encomenderos resultaron fundamentales, por sus servicios de guerra para el mantenimiento del control sobre el territorio. Este protagonismo les otorgó una amplia libertad para poder ignorar las ordenanzas de Alfaro. A su vez, la demografía indígena sufrió una estrepitosa caída debido a la continuidad del servicio personal, las guerras y desnaturalizaciones. Consideramos entonces que, en el caso catamarqueño, las consecuencias de la desestructuración fueron tan grandes, que dejaron muy pocas posibilidades para la adaptación y resistencia de los indígenas una vez insertos al sistema colonial -aunque éstas no fueron inexistentes. 


\section{La jurisdicción de Catamarca en la visita de Luján de Vargas}

La visita de Luján de Vargas es un documento muy interesante para analizar el estado de las encomiendas de Catamarca a finales del siglo XVII. Ésta da cuenta de cómo las consecuencias de la guerra definieron las formas de explotación de los indígenas y su modo de inserción en el mundo colonial. La propia naturaleza de la fuente, que cuenta con un cuestionario que se repitió en todas las jurisdicciones, facilita la comparación entre regiones y permite pensar cuáles eran las características particulares de Catamarca dentro de la gobernación. Asimismo, si bien este documento fue intensamente abordado para el estudio de distintas jurisdicciones del Tucumán, son pocos los trabajos que lo toman como objeto de estudio central para el análisis del caso catamarqueño. ${ }^{5}$

Entre 1692 y 1694 Luján de Vargas recorrió las distintas jurisdicciones del Tucumán interrogando a indígenas y feudatarios. La visita fue motivada por las denuncias realizadas al rey por el obispo del Tucumán, acerca de los abusos que los indígenas sufrían a manos de sus encomenderos. El objetivo del Visitador era reactualizar la vigencia de las ordenanzas de Alfaro y de la Recopilación de 1680. Pretendía restituir los indígenas a los pueblos de indios o asignarles tierras a aquellos que residían fuera de ellos, desagraviar a los indios encomendados, recordándoles su carácter de vasallos del rey y renovando el pacto colonial. Además, multó a los encomenderos que contravinieron las ordenanzas y buscó imponer el poder regio por sobre los intereses locales (Castro Olañeta, 2017: 18).

Salvo en la jurisdicción de Córdoba las visitas no se hicieron in situ, en las reducciones o en las chacras donde residían los indios, sino que el visitador se estableció en la ciudad cabecera de cada jurisdicción, excepto en Santiago del Estero, donde realizó su encuesta desde el pueblo de indios de Soconcho. Una vez instalado en la ciudad de Catamarca, el visitador ordenó a indios y encomenderos concurrir a su presencia para interrogarlos, modalidad que propició el subregistro de indígenas en los padrones. Por su parte, la visita no permite dar cuenta de la situación de la totalidad de los indígenas de la gobernación, en tanto su unidad de análisis era la encomienda, y por lo tanto escapó a los ojos del visitador todo el universo de indios que no estaban encomendados y porque, se supone, que no todos los encomenderos logaron llegar al encuentro con el visitador.

Las noticias de la visita generaron mucha expectativa entre los indígenas y los encomenderos del Tucumán y ambos grupos se prepararon para la llegada de Luján de Vargas. El documento da cuenta de cómo, en muchos casos, los feudatarios modificaron los comportamientos que significaban la violación de algunas ordenanzas, a la espera de poder evadir las multas del oidor de la Audiencia de Charcas. En Catamarca, algunos encomenderos dejaron de obligar a sus indias a hilar o comenzaron a pagar el trabajo a los indios. En otros casos, la ausencia de denuncias deja en evidencia la existencia de posibles pactos entre indios y feudatarios, previos a la llegada del visitador.

Los indígenas fueron interrogados por un cuestionario de cinco preguntas. La primera refería a la existencia o no de pueblo de indios, la segunda a las características del sistema tributario, la tercera al trabajo de las indias, poniendo énfasis en la entrega de hilados, la cuarta interrogaba sobre la violencia ejercida por los encomenderos y la quinta sobre la existencia de alquileres de indios. A partir de la respuesta a estas preguntas los indígenas tenían la oportunidad de denunciar a sus encomenderos por variados motivos, como sacas de indios
5. La visita de Luján de Vargas fue analizada por primera vez por Gastón Doucet (1980a y 1980b), posteriormente fue ampliamente abordada para el estudio de las distintas jurisdicciones de la gobernación. Para el caso de La Rioja contamos con los trabajos de Roxana Boixadós (2002 y 2003), para Santiago del Estero con los de Judith Farberman (2002), para Tucumán con los de Estela Noli (2003), para Córdoba con los de Isabel Castro Olañeta (2015a y 2015b) y Beatriz Bixio (2009), para Jujuy con los de Carlos Zanolli (2003) y para Salta el reciente trabajo de Isabel Castro Olañeta (2018), entre otros. Asimismo, Farberman y Boixadós (2006) realizaron un estudio comparativo de la visita a escala de la gobernación. En el caso de Catamarca, Gabriela de la Orden de Peracca (2018) publicó un estudio introductorio sobre el documento. Además, la visita de Luján de Vargas ha sido publicada íntegramente de manera parcelada. En este trabajo utilizamos la vista a Catamarca editada por Isabel Castro Olañeta (2017), titulada Visita del oidor Antonio Martínez Luján de Vargas a las encomiendas de Catamarca, Santiago del Estero y Salta: Gobernación del Tucumán, 1693-1694. 
6. Para una descripción más detallada sobre la visita de Luján de Vargas ver los estudios introductorios de Gastón Doucet (1980a) y de Isabel Castro Olañeta (2017).
7. A fin de enfatizar las particularidades catamarqueñas, haremos una brevísima síntesis del contexto del resto de las jurisdicciones de la gobernación del Tucumán. A partir del análisis de la visita de Luján de Vargas, Judith Farberman y Roxana Boixadós dieron cuenta de la diversidad de situaciones en las que se encontraban las sociedades indígenas dentro de la gobernación. En algunas jurisdicciones, los indígenas habían logrado una mayor capacidad de inserción al mundo colonial, lo cual tuvo un importante impacto en las formas de tributación que, en muchos casos, dejó atrás el servicio personal. En La Rioja, Salta, Santiago del Estero y San Miguel de Tucumán la tasa podía pagarse mediante trabajo indígena en sus pueblos o en las tierras de su encomendero. Asimismo, en las últimas dos jurisdicciones, los indígenas pudieron aprovechar a su favor la competencia entre encomenderos y otros españoles por la fuerza de trabajo indígena, contratándose con terceros por un salario mayor al que pagaban sus feudatarios. El servicio de carretería fue otra forma de pago de la tasa extendido en La Rioja, Santiago y Salta. En Jujuy los indígenas conservaban una fuerte historia de participación en los circuitos mercantiles, lo que les permitía tributar entregando servicios de carga de mercancías en el comercio regional. Asimismo, otra forma importante del pago de tributo fue a partir de la entrega de hilados por parte de las mujeres. Todas estas formas de pago de la tasa convivieron con servicio personal a la antigua usanza, en mayor o menos medida, dependiendo de la encomienda y la jurisdicción (Farberman y Boixadós, 2006). A continuación, veremos que la particularidad de Catamarca reside en la continuidad del servicio personal sin respeto de la tasación. de los pueblos, carencia de tierras, falta de pago por los trabajos, violencia. Luego de declarar, casi siempre mediando un intérprete, el notario pasaba por escrito una síntesis de lo dicho por los indios. En base a las denuncias, el visitador elaboraba cargos contra los feudatarios, frente a los cuáles éstos se defendían. Finalmente, se dictaba sentencia (Doucet, 1980a). El documento nos da información sobre el tamaño de las encomiendas, la existencia de pueblos de indios, las formas de tributación, la participación de los indígenas en los circuitos mercantiles y el acceso al usufructo de la tierra, entre otras cosas. ${ }^{6}$

Uno de los objetivos de la visita consistía en el desagravio de los indígenas que se lograba al momento de la sentencia. Luján de Vargas multó a los feudatarios por la contravención de las ordenanzas aunque en Catamarca, en todos los casos, moderó dichas multas por la pobreza de los encomenderos. No obstante, los condenó a pagar los trabajos adeudados a los indios y a restituirlos a los pueblos de indios o señalarles tierras en caso de que no tuvieran. Las multas y deudas eran pagadas ante el visitador en el momento de la sentencia, pero desconocemos si en Catamarca los señalamientos de tierra fueron efectivamente llevados a cabo.

El documento da cuenta de las particularidades de la región catamarqueña que la diferenciaban del resto de la gobernación. ${ }^{7}$ La gran cantidad de encomiendas y el pequeño número de indígenas comprendidos en ellas dan la pauta de las severas consecuencias desestructurantes que la explotación bajo servicio personal y las guerras habían tenido. La visita a Catamarca presenta 72 encomiendas, lo que la convertía en la jurisdicción con mayor cantidad de repartimientos. Sin embargo, éstas estaban conformadas por sólo 257 tributarios. Si bien la información demográfica debe ser tomada con cautela, dado que no fue tomada in situ, el panorama que muestra la visita es de gran cantidad de encomiendas con muy pocos tributarios, con un alto componente de indígenas desnaturalizados del Chaco y los valles calchaquíes. La mayoría de éstos estaban situados en tierras privadas aunque otros tenían pueblos de indios. Los feudatarios eran pobres y eso se refleja en las peticiones que realizaron los encomenderos ante el visitador, y en la explícita moderación que tuvo Luján de Vargas a la hora de multarlos.

\section{Los encomenderos catamarqueños}

Para poder comprender el carácter de la relación que se daba entre indígenas y encomenderos en Catamarca debemos hacer referencia a las características de este último grupo a finales del siglo XVII. Veremos que la gran pobreza de los feudatarios propiciaba formas de explotación de la fuerza de trabajo bajo servicio personal, en un contexto que definimos como doméstico.

A finales del siglo XVII, la riqueza del grupo de encomenderos de Catamarca se construía sobre la posesión de la tierra y la tenencia de repartimientos de indios. Pero tanto las tierras fértiles como la población indígena eran escasas en la jurisdicción. Las principales actividades económicas eran agroganaderas, concentrándose la mayoría de las chacras en el valle de Catamarca -la zona más fértil. La colonización del valle tuvo una dinámica particular. Por un lado, las grandes mercedes de tierra otorgadas a los primeros conquistadores fueron escasas y se fragmentaron con el tiempo, conforme a su división por herencia o entrega de tierras en forma de dote, o debido a conflictos entre los miembros de la elite en torno a la propiedad. Por otro lado, ciertos españoles no pertenecientes a las familias principales fueron logrando acceder a la 
propiedad de la tierra mediante donaciones, compras o instalación en tierras vacías (Sosa Miatello y Lorandi, 1991: 183-184). Para el momento de la llegada de Luján de Vargas, Catamarca era un espacio eminentemente rural, con su ciudad cabecera todavía en proceso de construcción, cuyos vecinos residían en el campo por no contar con los medios económicos para poder trasladarse a la ciudad. Esta condición se mantuvo hasta mediados del siglo XVIII, cuando San Fernando del Valle de Catamarca empieza a aumentar su población y el espacio, en general, comienza a reestructurarse. Por último, la región ofrecía pocas posibilidades de insertarse en los circuitos comerciales de larga distancia por las complicaciones que ofrecía su geografía (Lorandi y Schaposchnik, 1990; Sosa Miatello y Lorandi, 1991).

Dicho esto, en el contexto de pobreza generalizada la visita permite diferenciar dos grupos dentro del universo de encomenderos catamarqueños. Por un lado, un número relativamente pequeño de feudatarios, descendientes o vinculados con familias prestigiosas de los primeros conquistadores y fundadores de ciudades. Estos encomenderos contaban con prestigio social por sus apellidos y además formaban el núcleo más rico y poderoso de la elite catamarqueña. Eran poseedores de las encomiendas más grandes, generalmente situadas en pueblos de indios, y de las propiedades más extensas, participaban del comercio regional vendiendo ganado a otras jurisdicciones y monopolizaban el control sobre los cargos del cabildo. ${ }^{8}$

Por debajo de este selecto grupo de feudatarios, que detentaba el poder político y económico de Catamarca, había un segundo grupo de encomenderos con menos recursos, poseedores de encomiendas diminutas. Estas encomiendas, entregadas en la segunda mitad del siglo XVII a quienes participaron como soldados en las guerras contra los calchaquíes y en las campañas al Chaco, se componían de indígenas desnaturalizados entregados en piezas. La gran cantidad de soldados devenidos en encomenderos es una particularidad del espacio catamarqueño.
8. Para un análisis pormenorizado sobre una familia de la élite catamarqueña a finales del siglo XVII y principios del XVIII ver De la Orden de Peracca (2001).

\begin{tabular}{|l|c|l|l|l|l|}
\hline \multicolumn{1}{|c|}{ Encomendero } & Trib. & \multicolumn{1}{|c|}{ Encomendero } & Trib. & \multicolumn{1}{c|}{ Encomendero } & Trib. \\
\hline Jerónimo de Herrera & 3 & José Narváez & 2 & Lorenzo Cabral & 1 \\
\hline Bartolomé Ramírez de Sandoval & 5 & José Narváez (Corona) & 1 & Nicolás Gutiérrez & 1 \\
\hline Alonso de Tula & 2 & Juan Pérez de Hoyos & 1 & Gil de Agüero (Corona) & 2 \\
\hline Diego de Vera & 3 & En cabeza del rey & 6 & Pedro José de Morales & 1 \\
\hline Antonio González del Pino & 2 & Antonio Fernández & 1 & Sargento Mayor Pedro Arias & - \\
\hline Andrés de Ahumada & 1 & Antonio Orellana & 2 & Capitán Pedro Arias & 1 \\
\hline Doña Francisca Bustos de Villegas & 7 & Juan García & - & Lázaro Gómez & \\
\hline Miguel de Salazar & 1 & Esteban de Contreras & 3 & Bernabé Abad & 1 \\
\hline Bartolomé Reinoso & 1 & Diego Carrizo & 8 & Diego de Pedraza & 1 \\
\hline Don Joseph de Leyba & 2 & Bartolomé López Romero & - & Don Fernando Vanegas & 1 \\
\hline Nicolás de Herrera & 3 & Andrés de la Vega y Castro & 6 & Domingo de Tejeda & 1 \\
\hline Don Gaspar de Guzmán & 11 & Pedro Rodríguez & 7 & Melchor Orellana & 1 \\
\hline Ignacio de Agüero & 4 & Nicolás de Barrios Sarmiento & 4 & Doña María Pallares & 1 \\
\hline Doña Rafaela de Herrera & - & Nicolás de Barrios Sarmiento (Corona) & 1 & Juan de Nieva & 1 \\
\hline Adriano de Acosta & 2 & Doña Isabel Nieto Príncipe & - & Diego de Agüero & - \\
\hline Sebastián de Espeche & 1 & Francisco de Orellana & 1 & Diego de Agüero (Corona) & 1 \\
\hline Juan González Pacheco & 1 & Antonio de Acosta & 1 & Andrés de Olivera & 1 \\
\hline José Espinosa de Monteros & 1 & Doña María Magdalena Bazán de Pedraza & 2 & Juan Romero & - \\
\hline Doña Bárbara de Herrera & 3 & Agustín de Pedraza & 2 & Juan Ponce de Córdoba & 2 \\
\hline Domingo de Maidana (Corona) & 3 & Don Francisco de Villagra & - & & \\
\hline
\end{tabular}

Fuente: elaboración propia a partir de los datos de la visita.

Cuadro 1. Encomiendas de la jurisdicción de Catamarca situadas en propiedades privadas a partir de la visita de Luján de Vargas. 
9. Con 72 encomiendas Catamarca era la jurisdicción con más repartimientos de la gobernación pero, como se expresó, éstos eran diminutos, contando 257 tributarios. Si se lo contrasta con otras zonas de la gobernación la diferencia es grande. Córdoba contaba con 166 tributarios en 32 encomiendas; La Rioja con 337 en 53; Santiago con 553 en 31; San Miguel con 278 en 31; Salta con 316 en 30; y Jujuy con 190 en 9. Las encomiendas catamarqueñas eran, con mucha diferencia, las más pequeñas. Números tomados de Doucet (1980a: 236).
El Cuadro 1 muestra todos los repartimientos de Catamarca donde los indios estaban situados en propiedades particulares. Como puede apreciarse, la jurisdicción presenta una gran cantidad de feudatarios con encomiendas diminutas. De las 59 encomiendas que muestra el cuadro, sólo siete casos contaban con cinco o más tributarios, y algunas encomiendas ni siquiera los tenían y estaban formadas por indias, chinas o niños. Estos encomenderos eran propietarios de pequeñas parcelas de tierra. ${ }^{9}$

Los feudatarios no dejaron de hacer notar su pobreza al visitador. Sin duda se trataba de excusas para intentar evitar las multas pero también reflejaban la realidad de la región. Un argumento central que utilizaron para justificar su falta de recursos fueron los servicios de guerra. Desde mediados del siglo XVII los encomenderos de Catamarca debieron participar en las últimas guerras contra los calchaquíes y luego en las campañas contra los indígenas de la frontera chaqueña. La guerra contra los indígenas del Chaco se constituyó en una importante sangría de recursos para la economía del Tucumán colonial (Garavaglia, 1986a). Por ejemplo, Pedro Félix de Maidana, encomendero del pueblo de Motimo, declaraba ante Luján de Vargas:

yo por la obligacion de encomendero he estado assistiendo a lo que hera de mi obligacion en todas las funciones que se ofrezen en esta ciudad y entradas a la provincia del Chaco con exsorbitantes gastos sin que alcance las tassas que me pueden dar mis encomendados (Visita a-Catamarca, Castro Olañeta, 2017: 68).

El mismo argumento utilizaron los encomenderos Antonio González del Pino, José Narváez y Juan Pérez de Hoyos (Visita a Catamarca, Castro Olañeta, 2017: 75, 159, 163 respectivamente). Incluso un encomendero de la élite como Francisco de Nieva y Castilla había quedado fuertemente endeudado tras su participación en la represión del Gran Alzamiento Diaguita (De la Orden de Peracca, 2006: 64).

En síntesis, a finales del siglo XVII los encomenderos catamarqueños eran muy pobres. Esta condición estaba determinada por la pobreza relativa de la tierra, la fragmentación de las propiedades rurales y la marginalidad de la jurisdicción dentro de los circuitos comerciales de larga distancia, y se agravaba debido a las obligaciones militares de los feudatarios. A su vez, la disminuida población indígena estaba repartida en una gran cantidad de encomiendas, de las cuales la inmensa mayoría eran diminutas y formadas por indígenas desnaturalizados. Todo esto, como veremos, condicionó la forma en que la mano de obra indígena era explotada bajo servicio personal.

\section{Servicio personal en encomiendas domésticas}

Diversas investigaciones (Anello, 2002; De la Orden 2006, 2008, 2018; Farberman y Boixadós, 2006) dieron cuenta de la continuidad del servicio personal como forma de explotación de los indios en Catamarca a finales del siglo XVII. En este apartado pretendemos indagar sobre las características que tenía el servicio personal en Catamarca. Argumentamos que en esta jurisdicción se desarrolló un tipo de encomienda que podemos denominar como doméstica, que se definía por: su tamaño diminuto, la inexistencia de pago de tasa, la continuidad del servicio personal que se realizaba en una multiplicidad de tareas en las propiedades de los encomenderos, y la constante vigilancia que éstos imponían con un alto componente de violencia física para asegurar la explotación y el control de la fuerza de trabajo. Esta forma de explotación se 
daba en el ámbito doméstico, en tanto la mayoría de los indios residían en las propiedades de sus feudatarios.

Interrogados por la segunda pregunta de Luján de Vargas, en la totalidad de las encomiendas donde los indios presentaron quejas declararon no pagar tributo en especie ni en dinero, sino en servicio personal, y que lo hicieron en contra de su voluntad. ${ }^{10}$ Éste consistía en la entrega de trabajo directamente al encomendero en sus viñas, sementeras o algodonales y, en algunos casos, en el arreo de ganado hacia otras ciudades.

¿Qué carácter tenía este servicio personal? La respuesta a la segunda pregunta del cuestionario de Luján de Vargas dada por los indios calchaquíes de la encomienda de Juan León de Soria cuenta con varios elementos que nos permiten responder a este interrogante:

dijeron que no saven de tassa ni tributo sino es que le an pagado a su encomendero en el serbicio personal porque se lo mandaba y no de su boluntad y que este trabajo a sido continuo assi destos declarantes como de todos los demas que no a abido conçierto fijo y determinado sinos lo que el encomendero queria y se reduce a cinco baras de pañete para bestirçe y esto les solian dilatar dos o tres años que les esta debiendo (Visita a Catamarca, Castro Olañeta, 2017: 42).

El trabajo de continuo, la entrega de ropa para vestirse, los atrasos en los pagos y las deudas son características que aparecen en el fragmento citado y se repiten en todas las encomiendas. Según Roxana Boixadós, la referencia a la continuidad del trabajo en las declaraciones de los indígenas indica que se trataba de servicio personal, y no de una forma de pago de la tasa en trabajo, ya que no estaba establecido un límite de tiempo (Boixadós, 2002: 41). Además, los indígenas trabajaban a cambio de la ropa para vestirse y ni siquiera se les pagaba todos los años sino que el encomendero les estaba debiendo. Las declaraciones de indios de otras encomiendas completan el cuadro de explotación bajo servicio personal a finales del siglo XVII en la región. Los indios de la encomienda de Nicolás de Barrios declararon servir a su encomendero "todo el año" contra su voluntad y los indios de la encomienda de Bartolomé Romero declararon que por los servicios personales el encomendero "solo les solia dar de bestir muy de tarde en tarde y muy poco de comer" (Visita a Catamarca, Castro Olañeta, 2017: 205 y 183).

La visita pone de manifiesto un completo incumplimiento de la tasación del tributo establecida por Alfaro, y que no existía un criterio definido de pago a los indígenas por parte de los encomenderos. Mientras que los indios en casi todos los casos denunciaron la falta de pago, los encomenderos se defendieron argumentando que habían remunerado los cinco pesos de la tasa y el trabajo excedente. El encomendero don Luis de Quiroga declaró "les a pagado su trabajo en darles veinte pessos dentrando los cinco pesos del tributo por año" (Visita a Catamarca, Castro Olañeta, 2017: 290). Sin embargo, los encomenderos mintieron ante el visitador, ya que no existía una real aplicación de la tasación del tributo impuesta por Alfaro. Esto se hace evidente en la imposibilidad de realizar un cálculo del valor de los servicios personales entregados, ya que los indios trabajaban todo al año sin límites de tiempo.

Pero, además, tampoco se puede evaluar un criterio unitario compartido por los encomenderos para la entrega de productos a los indios a cambio de su trabajo, ya que estas entregas eran muy disímiles entre sí para trabajos similares.
10. En rigor, este tipo de respuesta se dio en todas las jurisdicciones. Sin embargo, análisis rigurosos de la información aportada por las declaraciones indígenas dieron cuenta de que, en otras regiones del Tucumán, bajo la denominación "servicio personal" muchas veces se escondían en realidad formas de tributo tasado. Sin embargo, esta transformación no se dio en la jurisdicción de Catamarca. Ver Farberman y Boixadós (2006). 
11. Los indígenas ya eran conocedores de la institución de la visita, en tanto ya habían sido visitados en otras oportunidades -las encomiendas de Catamarca fueron visitadas en $1667,1672,1681$ y 1690 . Es decir que los indígenas contaban con experiencias previas que les habían permitido conocer sus derechos y cómo reclamarlos frente al visitador. De cualquier manera, la visita de Luján de Vargas tiene un carácter especial por ser la única realizada por un oidor de la Audiencia de Charcas desde que Alfaro recorrió la gobernación.
Las formas de pago resultaban bastante arbitrarias según la encomienda, y en los casos en que los encomenderos referían a los pagos realizados en productos sin especificar su valor monetario es difícil hacer comparaciones. En todos los casos, los indios aclararon que no tenían conocimiento del jornal que debían ganar cada año y se deja de manifiesto la completa falta de conciertos. Resaltamos que las declaraciones de los encomenderos en torno a los pagos por el trabajo contrastan fuertemente con las declaraciones de los indígenas. Los indios, en la mayoría de los casos, limitaron los pagos a una prenda para vestirse entregada una vez al año o cada dos años. Así, las declaraciones de los encomenderos resultan una exageración para justificarse frente al visitador.

Hay que destacar una cuestión central: que esta forma de trabajo y remuneración se repite tanto en los pueblos de indios como en las encomiendas donde los indios estaban situados en tierras privadas. En ese sentido, la existencia o no de pueblo de indios no modificaba las formas de explotación de la fuerza de trabajo indígena. Esto contrasta con lo que sucedía en otras jurisdicciones, donde el sistema tributario sufrió modificaciones y, a grandes rasgos, el servicio personal continuó en las propiedades privadas mientras que en las reducciones se pagaba un tributo tasado (Farberman y Boixadós, 2006: 615).

A pesar de la falta de aplicación de las ordenanzas, los indígenas eran conscientes de la ilegalidad del servicio personal y aprovecharon el momento de desagravio, que la visita implicaba, para dar cuenta de que los productos que recibían a cambio de su trabajo no llegaban a cubrir el valor de todo el tiempo trabajado. ${ }^{11}$ Sin embargo, tampoco los indígenas hicieron un cálculo de lo que se les adeudaba. Eso se percibe en algunas expresiones: como cuando los indios declararon que sólo les entregaron ropa, o que el encomendero les entregaba lo que él quería, o como en el caso del indio Joseph de la encomienda de Juan Pérez de Hoyos, cuando explícitamente declararon "estarle debiendo su trabajo y no aberle pagado enteramente" (Visita a Catamarca, Castro Olañeta, 2017: 162).

En síntesis, la visita de Luján de Vargas da cuenta de la continuidad del servicio personal en las encomiendas catamarqueñas a finales del siglo XVII y sus características. El servicio personal estaba generalizado en todas las encomiendas, tanto en los pueblos como en las propiedades privadas y no se respetaba la tasación del tributo. Dada la pobreza de los encomenderos, indígenas y feudatarios compartían el espacio doméstico, y la explotación bajo servicio personal era ejercida directamente por el encomendero a nivel cotidiano. En este contexto de trabajo continuo, era imposible calcular la cantidad de tiempo de trabajo y el valor de la demasía de tasa, y la entrega de géneros apenas llegaba a cubrir la reproducción material de los indios. A pesar de todo, esto no impidió que los indígenas, conscientes de las transgresiones a las ordenanzas de Alfaro, reclamaran los pagos que se les adeudaban por los trabajos realizados.

\section{El trabajo de las indias}

La tercera pregunta del cuestionario de la visita es la que nos aporta información sobre los trabajos que realizaban las indias de las encomiendas. Las mujeres realizaban una multiplicidad de tareas, que combinaban la producción de hilados de algodón con trabajos agrícolas en las propiedades de los encomenderos y servicios domésticos en las casas. Esto las convertía en una importante fuerza de trabajo para el encomendero. 
El trabajo textil estaba generalizado en las encomiendas de la jurisdicción de Catamarca, que se habían convertido en un espacio especializado en la producción de algodón y tejidos (Garavaglia, 1986b). Los encomenderos entregaban algodón a las indias, tanto casadas como solteras, quienes lo hilaban y se lo devolvían -y lo hacían en contra de su voluntad. En la mayoría de las encomiendas, las indias hilaban por tarea. Los feudatarios demandaban a cada india que hilara cinco onzas por semana, aunque el monto variaba según el caso.

Los estudios de Judith Farberman y Roxana Boixadós sobre la visita de Luján de Vargas dieron cuenta de que, en las jurisdicciones de Santiago del Estero y La Rioja el trabajo textil de las indias podía funcionar como forma de cancelar la tasa de sus maridos. Esto permitía que mientras las mujeres hilaban, los tributarios podían ocuparse de otros asuntos. En los casos en que la producción textil superaba el valor de la tasa, la demasía era remunerada por los encomenderos. De esta manera, en estos casos, no se trataba de servicio personal sino de pago del tributo (Boixadós, 2002; Farberman, 2002; Farberman y Boixadós, 2006).

En contraste, en Catamarca la producción de hilados por parte de las mujeres no constituía una forma de cancelar la tasa de sus maridos. Tanto indias como tributarios entregaban servicios personales a los encomenderos a tiempo completo y apenas recibían ropa o algo de comer a cambio. Como dijimos, no se podía hacer un cálculo del valor del trabajo a tiempo completo de los indígenas y no había un pago de la demasía de tasa. Esto tampoco sucedía con la producción textil.

¿Qué carácter tenía el trabajo textil de las indias? Las indias no recibían remuneración por los hilados de acuerdo a la cantidad entregada sino que el feudatario les daba de vestir y, en ocasiones, también la comida. La entrega de dos varas de bayeta era un pago genérico que se repetía en todas las encomiendas, independientemente de la cantidad de hilado producido. En algunos casos, los feudatarios entregaban otros productos junto a las dos varas de bayeta. Pero en ninguno se percibe que los encomenderos hicieran un cálculo de qué era lo que tenían que remunerar, de acuerdo a la cantidad de hilo entregado. En realidad, los géneros dados por los feudatarios a las indias eran para contribuir a su sustento, y no pagos por el producto. Por ejemplo, en la encomienda de Alonso González del Pino, la india Isabel declaró que:

la muger del encomendero les solia repartir cinco onssas de hilado a la semana a cada una y que esta que declara sin embargo de estar cirviendo en otros exercicios de cosinar y labar los más de los días solía ilar una onsa y que esta tarea la an hecho hasta agora un año que murio su encomendera y por este trabajo y el que hasta oy tiene esta que declara en serbicio del dicho su encomendero no les ha pagado cossa alguna que a este que declara agora tres meses le dio dos baras de bayeta y no mas (Visita a Catamarca, Castro Olañeta, 2017: 72).

La cita no sólo pone de manifiesto la arbitrariedad del pago del encomendero sino la pesada carga laboral que significaba la multiplicidad de obligaciones que recaían sobre las indias. Además de hilados y servicios domésticos, las mujeres realizaban trabajos agrícolas. De esta manera vemos que, a diferencia de lo sucedido en otras regiones donde la entrega de hilados se convirtió en una de las formas principales de cancelación del tributo, en la jurisdicción de Catamarca las indias siguieron siendo explotadas bajo servicio personal. Los productos recibidos a cambio de su trabajo apenas podían satisfacer las 
necesidades de comida y vestimenta y no resultaban pagos acordes a la cantidad de hilo entregado.

El carácter doméstico que tenía la explotación de los indígenas en las encomiendas catamarqueñas determinaba las exigencias de trabajo hacia las indias en tareas diversas. Esto convertía al trabajo de las mujeres en un valiosísimo recurso, cuya explotación no tenía ningún costo para el encomendero. Por ejemplo, el feudatario Ignacio de Agüero declaró ante Luján de Vargas que el pago a sus indias por tareas agrícolas en sus sementeras, viñas y algodonales se reducía al trigo, algodón y uvas que las indias pudieran recoger una vez levantadas las cosechas (Visita a Catamarca, Castro Olañeta, 2017: 129). Esto se da en el contexto de una jurisdicción donde los indios escaseaban y los repartimientos eran muy pequeños, por lo tanto el trabajo de los encomendados debía ser aprovechado al máximo por parte de los feudatarios, tanto de los tributarios como de las mujeres. Los casos de sacas de indas de sus ranchos para residir en casas de sus encomenderos donde servían a tiempo completo constituían la forma de mayor desarraigo para el cumplimiento del servicio personal.

\section{Los pueblos de indios de la jurisdicción de Catamarca}

La primera pregunta del visitador nos permite evaluar el estado de los pueblos de indios y el acceso indígena a la tierra. En un trabajo comparativo de la visita de Luján de Vargas a escala de la gobernación, Judith Farberman y Roxana Boixadós propusieron que la visita permite diferenciar entre dos tipos de encomiendas, aquellas situadas en pueblos de indios -a las que denominaron encomiendas-pueblo- y aquellas donde los indígenas residían en tierras particulares (Farberman y Boixadós, 2006). Por su parte, también Estela Noli (2003) planteó como condición importante la existencia o no de pueblos de indios, en tanto la reducción proporcionaba a los indígenas derechos legales sobre las tierras. Posteriormente, Isabel Castro Olañeta propuso analizar la visita de Luján de Vargas de manera diacrónica y procesual, ya que la información que aporta sobre las encomiendas en la región no sólo puede pensarse como una imagen estática sino que da cuenta de un conjunto muy variado de situaciones y procesos distintos que vivían las poblaciones encomendadas. Esto le permitió romper con la mirada dicotómica entre encomiendas pueblo y encomiendas situadas en tierras de los encomenderos para dar cuenta de matices y situaciones diversas en torno al acceso a la tierra por parte de los indios (Castro Olañeta, 2015b: 86).

Nos parece importante aplicar esta perspectiva de análisis de Castro Olañeta al espacio catamarqueño, donde el proceso de desestructuración sufrido por las comunidades indígenas fue particularmente agresivo. En este apartado analizamos el estado de los pueblos de indios y del acceso de los indígenas a la tierra. Para ello, se problematiza la categoría de "pueblo" que aparece en las respuestas de los indígenas a la primera pregunta del cuestionario, para dar cuenta de la variedad de situaciones que se escondían bajo esa denominación

Para analizar los pueblos de indios de Catamarca debemos preguntarnos por las características que debía tener un pueblo de indios para calificar como tal. Las ordenanzas de Alfaro dieron origen a las reducciones en el Tucumán y establecieron los elementos fundamentales para su existencia. La ordenanza número 20 establecía que todos los pueblos debían contar con una iglesia, mientras que la número 33 ordenaba la existencia de tierras de comunidad 
inalienables (Levillier, 1918: 301-305). La visita de Luján de Vargas retomó las leyes alfarianas, lo cual se expresa en el cuestionario. La primera pregunta interrogaba sobre la existencia de pueblo, poniendo énfasis en los dos elementos establecidos por las ordenanzas de Alfaro: la capilla y las tierras de comunidad.

Si bien la legislación nos permite dar una definición de cómo debía ser un pueblo de indios, la palabra "pueblo" no resulta una categoría transparente en los documentos. Alejandra Anello aclara que en las fuentes de Catamarca el término "pueblo" tiene un significado polisémico, puede referir tanto al pueblo como sitio como a la unidad de encomienda pero que, a pesar de su ambigüedad, siempre guarda relación con las tierras comunitarias (Anello, 2005: 7). Partiendo del análisis de las ordenanzas de Alfaro y del cuestionario de Luján de Vargas, Farberman y Boixadós proponen que el pueblo de indios requería de una estructura urbana nucleada en torno a una capilla, tierras inalienables, una comunidad que participara de los oficios religiosos, a lo que agregan la existencia de autoridades políticas e identificación étnica (Farberman y Boixadós, 2006: 609). Por su parte, Isabel Castro Olañeta considera necesarios tres elementos: tierras inalienables, autoridades políticas y la adscripción de los sujetos que viven en el pueblo a un sistema tributario específico (Castro Olañeta, 2006: 40).

Nosotros consideramos que la visita de Luján de Vargas da cuenta de trece pueblos de indios, ya que al ser interrogados por la primera pregunta del cuestionario en trece encomiendas los indígenas declararon tener pueblo. Ahora bien, el análisis de cada caso nos demuestra la existencia de situaciones diferentes en el estado de estos pueblos. En algunas encomiendas los indígenas declararon tener pueblo ante el visitador, a pesar de carecer de alguno o de todos los elementos mencionados como necesarios para ser considerados pueblos. En este sentido, la existencia o no de dichos elementos nos da pauta del estado en el que se encontraban lo que los indios llamaban "pueblo". Los hemos separado en cuatro grupos distintos según sus características:

1) Pueblos de indios propiamente dichos: Colpes, Huachaschi, Simogasta, Collagasta (encomienda de Carrizo de Andrada), Ingamana.

2) Pueblos en proceso de descomposición: Pipanaco, Tabigasta, Choya, Motimo, Collagasta (encomienda de Lucas de Figueroa).

3) Pueblos desaparecidos: Villapima, Ponai.

4) Pueblos repoblados: Yocagasta.

El Cuadro 2 presenta información demográfica de los pueblos, la existencia o no de autoridades étnicas y su ubicación geográfica. Podemos ver que aquellos que agrupamos bajo la categoría de pueblos de indios propiamente dichos son los que contaban con mayor cantidad de población y todos poseían autoridades étnicas. Mientras que los pueblos que consideramos en proceso de desestructuración tenían población más reducida y algunos carecían de autoridades. A continuación definimos las características de cada grupo.

1) Los pueblos de indios propiamente dichos eran aquellos que contaban con todos los elementos necesarios para ser considerados como tales -tierras de comunidad, autoridades étnicas, y comunidad de tributarios aunque no todos tenían iglesia- y existía un efectivo acceso al usufructo de las tierras del pueblo por parte de los indios. 


\begin{tabular}{|l|l|c|c|l|l|}
\hline \multicolumn{1}{|c|}{ Pueblo } & \multicolumn{1}{|c|}{ Encomendero } & Trib. & Pobl. & \multicolumn{1}{c|}{ Cacique } & Ubic. \\
\hline Yocagasta & León de Soria & 12 & 31 & No & Valle \\
\hline Villapima & Diego Navarro & 20 & 48 & Don Fernando Sigamba & Valle \\
\hline Ponai & Juan de Almonasi & 9 & 15 & No & Oeste \\
\hline Choya & Antonio de la Vega & 6 & 7 & Capitán don Cristóbal del Castillo & Valle \\
\hline Collagasta & Lucas de Figueroa & - & - & No & Valle \\
\hline Ingamana & Gregorio de Villagra & 26 & 74 & Don Francisco Liquemay & Oeste \\
\hline Pipanaco & Domingo de Pedraza & 9 & 24 & Don Ignacio Callavi & Oeste \\
\hline Colpes & Esteban de Nieva y Castilla & 19 & 58 & Don Cristóbal Sanquinay & Oeste \\
\hline Huachaschi & Joseph de Cabrera & 7 & 25 & Don Miguel & Oeste \\
\hline Collagasta & Diego Carrizo de Andrada & 7 & 19 & Don Felipe Pallamay & Valle \\
\hline Simogasta & Luis de Quiroga & 16 & 44 & Alonso Abayen (ausente) & Valle \\
\hline Tabigasta & Antonio Lobo & 2 & 6 & No & Este \\
\hline Motimo & Pedro Félix de Maidana & 4 & 14 & Don Cristóbal Ayunta & Valle \\
\hline
\end{tabular}

Fuente: elaboración propia a partir de los datos de la visita.

Cuadro 2. Pueblos de indios de Catamarca a partir de la visita de Luján de Vargas.

Estos pueblos fueron los que mejor resistieron el proceso de desestructuración, seguramente tanto por el acceso a las tierras comunales como también por la existencia de autoridades que permitieran llevar adelante estrategias colectivas de adaptación al mundo colonial. Así, podemos destacar que los habitantes de estos pueblos lograron resistir el efecto desestructurante que tenía la práctica de las sacas de indios. En varios de ellos, los indígenas denunciaron que el encomendero los sacaba para ir a trabajar a sus propiedades. Sin embargo, los indios lograron que ello no redundara en el abandono de sus reducciones y la pérdida definitiva de sus tierras. Los testimonios de los indios de Colpes, Simogasta y Collagasta -encomienda de Carrizo de Andrada- dan cuenta de que los pueblos tenían población permanente. Mientras que en el caso de Huachaschi, si bien había sufrido más el proceso de despoblamiento, los indios habían conseguido acceso al usufructo de tierras en la estancia del feudatario.

2) Los pueblos en proceso de descomposición eran aquellos prácticamente despoblados, producto del traslado de la población a estancias donde no existía el acceso efectivo a las tierras de comunidad y donde las autoridades étnicas habían desaparecido. Las sacas de indios jugaron un rol central en el despoblamiento y desestructuración de estos pueblos. Por ejemplo, los indios del pueblo de Collagasta "solo pidieron al señor bissitador los passase de la dicha estancia a su pueblo que es Collagasta donde estan algunos biejos y ay Yglesia". De igual manera, el pueblo de Tabigasta contaba sólo con dos tributarios que residían en tierras de su encomendero, aunque éstos declararon que "tienen pueblo que se llama Tabigasta" (Visita a Catamarca, Castro Olañeta, 2017: 164 y 294). Con la mudanza de los indios a las propiedades del encomendero, éstos perdían el acceso a la tierra porque el feudatario no les señalaba ninguna en sus chacras. El resto de los indios de estos pueblos denunciaron sacas con la consiguiente pérdida del acceso a la tierra de manera similar.

En el caso del pueblo de Choya, el avance del feudatario sobre las tierras de la reducción fue central en el proceso de descomposición. En efecto, los indios de Choya declararon que entregaban servicio personal

al dicho encomendero asi en las sementeras que siembran para él en el pueblo y tierras de dichos yndios como en los serbicios que les ocupa su biña y chacra 
[...] y que de las sementeras que le hasen en las tierras del dicho su pueblo no parten con él sino que se lo lleba todo (Visita a Catamarca, Castro Olañeta, 2017: 149).

No cabe duda de que esto contribuyó fuertemente a la descomposición del pueblo ya que, a pesar de contar con reconocimiento legal sobre sus tierras, los indios perdieron el usufructo efectivo sobre ellas.

3) Los pueblos desaparecidos eran aquellos que al momento de la visita ya no existían pero sus nombres se conservaban en la memoria de los indígenas. Es el caso de los indios de la encomienda de Juan de Almonasi, quienes dijeron ante el visitador que "tienen un pueblo nombrado Ponai pero que son nassidos en la chacra de Poman donde assisten que no les a señalado tierras su encomendero" (Visita a Catamarca, Castro Olañeta, 2017: 96). Los indios vivían en la chacra y habían nacido allí sin conocer el pueblo. No hay datos en la visita sobre la ubicación del pueblo que los indios declararon haber tenido y el oidor preguntó al encomendero dónde era que tenían los indios su reducción. Es decir que para 1693 habían desaparecido todos los elementos que conformaban un pueblo de indios.

Algo similar sucedió con el caso de Villapima. Encomendados por primera vez en 1591 a Alonso de Tula Cervin, en la primera mitad del siglo XVII los indígenas sufrieron el avance de distintos encomenderos sobre sus tierras y fueron trasladados de su asiento original. En 1661 el pueblo de Villapima fue reconocido como pueblo de indios con tierras comunitarias, cacique y cura doctrinero (Toranzo, 2008: 193). Sin embargo, para 1667 el pueblo ya no existía y el encomendero había trasladado a todos los indios a la estancia de Capayán, al sur del valle, donde estaban situados al momento de la visita de Luján de Vargas. A pesar de los constantes traslados y la desaparición de su reducción, los indios de Villapima emprendieron acciones colectivas para recuperar sus tierras. En 1667, aprovechando la visita del juez empadronador a la región, los indios litigaron contra su encomendero por el acceso al agua del río que recorría las tierras del pueblo de Villapima, que se les había arrebatado (Montes, 1961: 99). No sabemos cómo terminó este pleito, pero frente al visitador Luján de Vargas los indios de Villapima declararon

particular gusto y voluntad de quedarce en dicha estancia adonde el encomendero antesesor abia puesto y sacado de su pueblo que esta distante legua y media portener mejores comodidades aqu [...] y assi repitieron estar gustossos y contentos (Visita a Catamarca, Castro Olañeta, 2017: 58-59).

Seguramente, la acción de la comunidad había permitido llegar a un acuerdo con su encomendero y conseguir que se les señalaran tierras en la estancia. La fortaleza demográfica de la comunidad, la existencia de autoridades indígenas y su larga experiencia dentro del mundo colonial les habrían permitido a los indios desarrollar estrategias para lograr el acceso a la tierra, a pesar de la desaparición del pueblo de indios y los diversos traslados. ${ }^{12}$

Resulta interesante que, tanto en el caso de los pueblos en proceso de desestructuración como en el de los pueblos desaparecidos, los indígenas no dejaron de recordarle al visitador que ellos tenían pueblo. Es posible que pretendieran utilizar la visita como momento para recuperar el acceso a las tierras perdidas. En efecto, en muchos casos los indios pidieron ser devueltos a sus pueblos y el visitador ordenó a los encomenderos que los volvieran a reducir.
12. Existen estudios que dan la pauta de este tipo de acuerdos para otras zonas del Tucumán, como el caso del pueblo de San Francisco de Paipaya en Jujuy. Ver Sica (2002). 
4) Finalmente, en la categoría de pueblos repoblados colocamos al pueblo de Yocagasta, encomienda de León de Soria Medrano. Yocagasta fue una encomienda antigua, en la cual, a lo largo del siglo, los encomenderos avanzaron sobre las tierras de sus indios y los trasladaron a sus propiedades. Estas acciones tuvieron un fuerte impacto sobre su población (Larrouy, 1914). Hacia 1693, la visita de Luján de Vargas ya no da cuenta de la existencia de ningún indio originario en la encomienda pero Soria Medrano sí tenía indios desnaturalizados, calchaquíes y mocovíes, que declararon ser del pueblo de Yocagasta. De esta manera, si anteriormente había sido despoblado y había desaparecido el encomendero lo repobló situando ahí a los desnaturalizados.

\section{Conclusiones}

La dinámica particular de conquista del territorio catamarqueño, caracterizada por la tenaz resistencia de los pueblos indígenas, la guerra y las desnaturalizaciones, convirtió a los encomenderos en actores fundamentales para el control efectivo del territorio mediante los servicios de guerra. Esto dio lugar a un resultado paradójico: los encomenderos lograron un altísimo grado de autonomía como para seguir ignorando las ordenanzas de Alfaro hacia finales del siglo XVII, perpetuando el servicio personal, pero los efectos desestructurantes de las guerras, traslados y explotación hicieron estragos sobre la demografía indígena. La resultante fue encomenderos paupérrimos con capacidad de ignorar las ordenanzas.

Fue en este contexto que se desarrolló en Catamarca una forma de encomienda doméstica caracterizada por repartimientos muy pequeños, en su mayoría situados en tierras privadas, con explotación bajo servicio personal a tiempo completo y donde no se respetaba la tasación impuesta por Alfaro. En estas encomiendas, los feudatarios compartían el espacio doméstico con los indígenas y cumplían el rol de vigilantes de sus obligaciones. La violencia ejercida por los encomenderos era una característica importante en las relaciones hispano-indígenas, ya que el encomendero personalmente obligaba a los indios al trabajo e impartía castigos. Debido a la estrepitosa caída de la población indígena la fuerza de trabajo debía ser aprovechada al máximo, por lo que tanto tributarios como mujeres resultaban un recurso muy preciado y eran sometidos a una multiplicidad de tareas. En el caso de la producción de hilados, ésta no se tradujo en una forma de pago de la tasa sino que continuó el trabajo bajo servicio personal. En efecto, se trataba de una forma de explotación bastante similar a la etapa pre-alfariana.

Este profundo proceso de desestructuración condicionó las formas de acceso indígena a la tierra. Muchos pueblos de indios sufrieron un fuerte despoblamiento debido a las exigencias de trabajo por parte de los encomenderos, que se expresaba en la constante saca de indios de los pueblos. En la mayoría de los casos, estas sacas resultaban en la pérdida del acceso a la tierra dado que los encomenderos no les señalaban tierras en sus propiedades privadas. En contraste, en otros casos los indígenas lograron mantener sus pueblos habitados lo que les aseguraba el acceso al usufructo de las tierras de reducción. Sin embargo, a pesar del alto nivel de descomposición de algunos pueblos -o de su efectiva desaparición- los indígenas igualmente declararon tener pueblo de indios, seguramente intentando aprovechar la visita a su favor para recuperar las tierras perdidas. 
Destacamos que fue el alto grado de desestructuración lo que determinó la forma de inserción de los indígenas de Catamarca en el sistema colonial. Dicha desestructuración dificultó la posibilidad de adaptación de los indios al nuevo contexto colonial, lo que limitó su capacidad de acción y explica por qué no se dio una transformación en las formas de tributación en Catamarca, como ocurrió en otras jurisdicciones. Esto se refleja en la continuidad del servicio personal sin respeto de la tasación del tributo, la existencia de una encomienda de tipo doméstico y la debilidad de sus pueblos de indios.

Sin embargo, esto no impidió que los indígenas intentaran adaptarse a su nueva situación y llevaran adelante acciones de resistencia. Aprovecharon la presencia del visitador para exigir que se les pagaran las deudas, intentaron lograr el acceso a la tierra denunciando la falta de ellas o el despoblamiento de los pueblos y los maltratos. Asimismo, la adaptación se hace notar en los casos donde indios y encomenderos lograron acuerdos previos a la llegada del oidor y por eso no realizaron denuncias. Pero, a pesar de todo, el contexto catamarqueño fue mucho menos propicio que otras regiones del Tucumán para la adaptación y resistencia de los pueblos indígenas.

\section{Agradecimientos}

Una primera versión de este trabajo fue presentada como ponencia en las XVII Jornadas Interescuelas/ Departamento de Historia, en la Universidad de Catamarca en octubre de 2019. Agradezco mucho a Isabel Castro Olañeta sus comentarios que me permitieron mejorar el borrador inicial para su publicación. 


\section{Q Bibliografía}

"Anello, A. (2002). "Familia indígena y sociedad en el curato de Londres (Catamarca), terminando el siglo XVII" en Farberman J. \& R. Gil Montero (eds.), Los pueblos de indios del Tucumán colonial: Pervivencia y desestructuración: 101-138. Bernal, Universidad Nacional de Quilmes.

»Anello, A. (2005). Hijos de Caciques, Hijos del Montón. Una aproximación a la legitimidad filial desde el interés de los actores. Catamarca. S. XVII-XVIII. Actas de las VII Jornadas Argentinas de Estudios de Población. Tandil, 12 al 14 de octubre. Disponible en Internet: http://www.redaepa.org.ar/jornadas/viii/AEPA/B19/Anello.pdf. Consultada el: 8 de marzo de 2019.

» Bixio, B. (ed.). (2009). Visita a las encomiendas de indios de Córdoba: Transcripción y estudios sobre la visita de Antonio Martines Luxan de Vargas (Vol. 2). Córdoba, Brujas.

" Boixadós, R. (2002). "Los pueblos de indios de La Rioja colonia. Tierra, trabajo y tributo en el siglo XVII” en Farberman J. \& R. Gil Montero (eds.), Los pueblos de indios del Tucumán colonial: Pervivencia y desestructuración: 15-57. Bernal, Universidad Nacional de Quilmes.

" Boixadós, R. (2003). "La visita de Luján de Vargas a las encomiendas riojanas (1693): Comentarios, notas y lecturas posibles" en Boixadós R. y C. Zanolli, La visita de Luján de Vargas a las encomiendas de La Rioja y Jujuy (1693-1694). Estudios preliminares y fuentes.: 21-40. Bernal, Universidad Nacional de Quilmes.

" Boixadós, R. (2011). El fin de las guerras calchaquíes. La desnaturalización de la nación yocavil a La Rioja (1667). Corpus, 1 (1). http://ppct.caicyt.gov.ar/index.php/corpus/article/ view/250/95. Consultada el: 5 de enero de 2018

» Brizuela del Moral, F. y M. I. Acuña (2002). La jurisdicción territorial de Catamarca. Congreso Regional de Ciencia y Tecnología NOA, Secretaría de Ciencia y Tecnología (SECyT)/ Universidad Nacional de Catamarca, Catamarca.

»Carmignani, L. (2013). Política colonial y sociedades indígenas en la Gobernación del Tucumán. El gobernador Alonso de Ribera, los Tenientes de Naturales y la elite encomendera durante la vigencia de las Ordenanzas de Abreu. Síntesis 4: 1-24.

"Castro Olañeta, I. (2006). "Pueblos de indios en el espacio del Tucumán colonial” en Mata de López S. y N. Areces (eds.), Historia Regional. Estudios de casos y reflexiones teóricas: 37-49. Salta, EDUNSa.

"Castro Olañeta, I. (2010). Servicio personal, tributo y conciertos en Córdoba a principios del siglo XVII. La visita del gobernador Luis de Quiñones Osorio y la aplicación de las Ordenanzas de Francisco de Alfaro. Memoria Americana. Cuadernos de Etnohistoria 18 (1): 105-131.

»Castro Olañeta, I. (2015a). El oidor de Charcas, Antonio Martínez Luján de Vargas, y la nueva coyuntura a fines del siglo XVII en Tucumán. A propósito de los derechos a la tierra de los pueblos de indios. Memoria Americana. Cuadernos de Etnohistoria 23 (1): 39-67.

»Castro Olañeta, I. (2015b). Encomiendas, pueblos de indios y tierras. Una revisión de la visita del Oidor Luján de Vargas a Córdoba del Tucumán (fines siglo XVII). Revista Estudios del ISHiR 5 (12): 82-104.

"Castro Olañeta, I. (2017). Visita del oidor Antonio Martínez Luján de Vargas a las encomiendas de Catamarca, Santiago del Estero y Salta: Gobernación del Tucumán, 16931694. Córdoba, Ferreyra Editor. 
»Castro Olañeta, I. (2018). Las encomiendas de Salta (gobernación del Tucumán, siglo $\mathrm{XVII})$. Andes 2 (29): 1-41.

»De la Orden de Peracca, G. (2001). Familia y poder en Catamarca colonial. Los Nieva de Castilla (1630-1730). Memoria Americana. Cuadernos de Etnohistoria, 10: 95-138.

»De la Orden de Peracca, G. (2006). Pueblos indios de Pomán. Catamarca (siglos XVII a XIX). Buenos Aires, Dunken.

»De la Orden de Peracca, G. (2018). “Las encomiendas de Catamarca a fines del siglo XVII. Visita de Don Antonio Martínez Luján de Vargas” en de la Orden de Peracca G. (dir.), Visita de Don Antonio Martínez Luján de Vargas. Catamarca, 1693: 15-38. Rosario, Prohistoria Ediciones.

»De la Orden de Peracca, G. (coord.), (2008). Los pueblos de indios en Catamarca colonial. Catamarca, Facultad de Humanidades, Universidad Nacional de Catamarca/ Secretaría del Estado de Cultura de la Provincia de Catamarca.

» Doucet, G. (1980a). Introducción al estudio de la visita del oidor don Antonio Martínez Luján de Vargas a las encomiendas de indios del Tucumán. Boletín del Instituto de Historia Argentina y Americana «Dr. Emilio Ravignani» 26: 205-246.

» Doucet, G. (1980b). Los autos del visitador don Antonio Martínez Luján de Vargas. Revista de Historia del Derecho 8: 123-153.

» Doucet, G. (1990). “La encomienda de servicio personal en el Tucumán bajo régimen legal: Comentarios a las ordenanzas de Gonzalo de Abreu” en Levaggi Abelardo (ed.), El aborigen y el derecho en el pasado y el presente: 141-244. Buenos Aires, Universidad del Museo Social Argentino.

»Farberman, J. (2002). "Feudatarios y tributarios a fines del siglo XVII. Tierra, tributo y servicio personal en la visita de Luján de Vargas a Santiago del Estero (1693) en Farberman J. y Gil Montero R. (Eeds.), Los pueblos de indios del Tucumán colonial: Pervivencia y desestructuración: 59-90. Bernal, Universidad Nacional de Quilmes.

»Farberman, J. y R. Boixadós (2006). Sociedades indígenas y encomienda en el Tucumán colonial. Un análisis comparado de la visita de Luján de Vargas. Revista de Indias LXVI (238): 601-628.

» Farberman, J. y R. Gil Montero (2002). Los pueblos de indios del Tucumán colonial: Pervivencia y desestructuración. Bernal, Universidad Nacional de Quilmes.

» Garavaglia, J. C. (1986a). La guerra en el Tucumán colonial. Sociedad y economía en área de frontera (1660-1760). HISLA 4: 21-34.

» Garavaglia, J. C. (1986b). Los textiles de la tierra en el contexto colonial rioplatense: ¿una revolución industrial fallida? Anuario IEHS 1: 45-87.

» Guzmán, G. (1986). Historia Colonial de Catamarca. Buenos Aires, Milton Editores.

" Larrouy, A. (1914). Los indios del Valle de Catamarca. Estudio histórico. Revista de la Universidad de Buenos Aires XXVII: 155-213.

»Levillier R. (1918). Correspondencia de la ciudad de Buenos Aires con los reyes de España $1615-1635$ (Vol. 2). Biblioteca del Congreso Argentino.

» Lorandi, A. M. (1988a). El servicio personal como agente de desestructuración en el Tucumán colonial. Revista Andina 6 (1): 135-173.

»Lorandi, A. M. (1988b). La resistencia y rebeliones de los diago-calchaquí en los siglos XVI y XVII. Cuadernos de Historia 8: 99-122.

» Lorandi, A. M.yA. Schaposchnik(1990). Los milagros de la Virgen del Valle yla colonización de la ciudad de Catamarca. Journal de la Société des Américanistes 76: 177-198. 
» Montes, A. (1961). El Gran Alzamiento Diaguita, Revista Antropológica I: 89-159.

» Noli, E. (2003). Pueblos de indios, indios sin pueblos: Los calchaquíes en la visita de Luján de Vargas de 1693 a San Miguel de Tucumán. Anales Nueva Época 6: 329-363.

»Palomeque, S. (200o). “El mundo indígena. Siglos XVI-XVIII” en Tandeter E. (ed.), Nueva Historia Argentina 2: 87-144. Buenos Aires, Sudamericana.

» Paz, G. (2008). Dossier: Los pueblos de indios del Tucumán colonial revisitados. De la desestructuración a la identidad. Andes 19: 213-224.

»Quiroga, L. (2012). Las granjerías de la tierra: Actores, y escenarios del conflicto colonial en el valle de Londres (gobernación del Tucumán, 1607-1611). Surandino Monográfico 2 (2): 1-37.

» Sica, G. (2002). Vivir en una chacra de españoles: Encomienda, tierra y tributo en el pueblo de San Francisco de Paipaya, Jujuy, Siglo XVII" en Farberman J. y R. Gil Montero (eds.), Los pueblos de indios del Tucumán colonial: Pervivencia y desestructuración: 203-226. Bernal, Universidad Nacional de Quilmes.

» Sosa Miatello, S. y A. M. Lorandi (1991). Tierra y élites en Catamarca. Siglos XVII y XVIII. Historia y Cultura 20: 179-194.

" Toranzo, R. (2008). "Mestizaje en el pueblo de indios de Villapima del Valle Central de Catamarca. Siglos XVII y XVIII” en de la Orden de Peracca, G. (coord.), Los pueblos de indios en Catamarca colonial: 191-200. Catamarca, Facultad de Humanidades, Universidad Nacional de Catamarca/ Secretaría del Estado de Cultura de la Provincia de Catamarca.

"Zanolli C. (2003). “Análisis de la visita de Luján de Vargas a la jurisdicción de San Salvador de Jujuy (1694)” en Boixadóss, R y C. Zanolli (eds.), La visita de Luján de Vargas a las encomiendas de La Rioja y Jujuy (1693-1694). Estudios preliminares y fuentes: 41-63. Bernal, Universidad Nacional de Quilmes.

»Zelada, V. e I. Castro Olañeta (2017). Documentos sobre la guerra y la desnaturalización calchaquí. Los autos del gobernador Alonso de Mercado y Villacorta. Revista TEFROS 15 (1): 188-213. 